\title{
Os referenciais teórico-metodológicos nas pesquisas sobre políticas públicas de educação ambiental: articulando e aprofundando os conceitos de Estado, sociedade civil e políticas públicas
}

\section{The theoretical and methodological references in research on public policies of environmental education: articulating and deepening the concepts of State, civil society and public policies}

\section{Las referencias teóricas y metodológicas en la investigación sobre políticas públicas de educación ambiental: articulación y profundización de los conceptos de Estado, sociedad civil y políticas públicas}

\author{
Eduardo da Costa Pinto D'Avila ${ }^{1}$ \\ Leonardo Kaplan ${ }^{2}$ \\ Rodrigo Lamosa ${ }^{3}$
}

\begin{abstract}
Resumo
A proposta deste artigo é identificar os principais referenciais teórico-metodológicos e autores presentes nas pesquisas sobre as políticas públicas de educação ambiental (EA), tomando como base os trabalhos aprovados nos Encontros Pesquisa em Educação Ambiental (X EPEA), no Grupo de Discussão de Pesquisa (GDP) sobre Políticas Públicas de Educação Ambiental, ocorridos entre 2011 e 2019. Além disso, pretende-se realizar uma análise comparativa desses trabalhos, destacando os objetivos, referenciais e temas. O estudo é parte de um movimento que vem sendo realizado nesse GDP desde 2009, com a construção coletiva de uma agenda de pesquisas que busca levantar questões comuns para os pesquisadores desse subcampo, no sentido de avançar nas discussões travadas, seja nas próprias pesquisas, seja durante os encontros de pesquisa. Este artigo, portanto, se soma ao conjunto de iniciativas do GDP e de pesquisadores que entendem que o fortalecimento do campo científico pressupõe o adensamento teórico das pesquisas realizadas.
\end{abstract}

Palavras-chave: Políticas públicas. Educação Ambiental. Estado.

\begin{abstract}
The purpose of this article is to identify the main theoretical-methodological references and authors present in research on public policies of environmental education (EA), based on the works approved in the Research Meetings in Environmental Education (X EPEA), in the Research Discussion Group (GDP) on Public Policies of Environmental Education, which occurred between 2011 and 2019. In addition, it is intended to perform a comparative analysis of these works highlighting the objectives, references and themes. This study is part of a movement that has been carried out in this GDP since 2009, with the collective construction of a research agenda that seeks to raise common questions for researchers in this subfield, in order to advance in the discussions held either in the research itself or during the research meetings. This paper, therefore, adds to the set initiatives by GDP and researchers who understand that the strengthening of the scientific field presupposes the theoretical densification of the researches carried out.
\end{abstract}

Keywords: Public policy. Environmental Education. State.

\footnotetext{
${ }^{1}$ Professor Doutor de Sociologia do Instituto Federal de Educação, Ciência e Tecnologia (IFRJ), Campus Duque de Caxias. Av. República do Paraguai, 120, Vila Sarapuí, Duque de Caxias. E-mail: eduardocdavila@gmail.com

2 Professor Doutor da Faculdade de Educação da Universidade do Estado do Rio de Janeiro (EDU/UERJ), Departamento de Estudos Aplicados ao Ensino (DEAE). leonardokaplan@gmail.com

${ }^{3}$ Professor Doutor da Universidade Federal Rural do Rio de Janeiro e do Programa de Pós-Graduação em Educação, Demandas Populares e Contextos Contemporâneos (PPGEduc/UFRRJ). rodrigo1281 @ yahoo.com.br.
} 


\section{Resumen}

El propósito de este artículo es identificar las principales referencias teórico-metodológicas y autores presentes en la investigación sobre políticas públicas de educación ambiental (EA), sobre la base de los trabajos aprobados en las Reuniones de Investigación en Educación Ambiental (X EPEA), en el Grupo de Discusión en Pesquisa (GDP) sobre Políticas Públicas de Educación Ambiental, que ocurrieron entre 2011 y 2019. Además, se pretende realizar un análisis comparativo de estas obras, destacando los objetivos, referencias y temas. Este estudio forma parte de un movimiento que se ha llevado a cabo en este GDP desde 2009, con la construcción colectiva de una agenda de investigación que busca plantear cuestiones comunes a los investigadores en el subcampo, con el fin de avanzar en los debates celebrados, ya sea en la propia investigación o durante las reuniones de investigación. Este artículo, por lo tanto, se suma al conjunto de iniciativas de GDP e investigadores que entienden que el fortalecimiento del campo científico presupone la consolidación teórica de las investigaciones.

Palabras clave: Políticas públicas. Educación Ambiental. Estado.

\section{Introdução}

A proposta deste artigo é identificar os principais referenciais teórico-metodológicos e autores presentes nas pesquisas sobre as políticas públicas de educação ambiental (EA), tomando como base os trabalhos aprovados nos Encontros Pesquisa em Educação Ambiental (X EPEA), no Grupo de Discussão de Pesquisa (GDP) sobre Políticas Públicas de Educação Ambiental, ocorridos entre 2011 e 2019. Além disso, pretendemos realizar uma análise comparativa desses trabalhos, destacando os objetivos, referenciais e temas. O estudo é parte de um movimento que vem sendo realizado nesse GDP desde 2009, com a construção coletiva de uma agenda de pesquisas que busca levantar questões comuns para os pesquisadores desse subcampo, no sentido de avançar nas discussões travadas seja nas próprias pesquisas, seja durante os encontros de pesquisa. A cada EPEA novas questões são adicionadas a essa agenda de pesquisas, e algumas das que estavam indicadas vem sendo discutidas pelos pesquisadores. Atualmente, essa agenda conta com 22 eixos temáticos, a saber:

1. Os conceitos de Estado e sociedade civil nas políticas públicas de educação ambiental.

2. Limites e estratégias para que as políticas públicas possam se constituir como políticas de Estado, políticas estruturantes, mais densas e menos instáveis.

3. As tensões indivíduo-instituição na formulação das políticas públicas.

4. O lugar das políticas públicas em educação ambiental no Estado (o quão estratégicas elas são, se são marginais... que condições têm para sair desse lugar mais marginalizado?).

5. A relação das políticas públicas de educação ambiental com outras políticas públicas, destacadamente, as de educação (reiteradas várias vezes), mas também as demais políticas sociais, de saneamento, de saúde etc.

6. Estudo das condições objetivas das políticas públicas de educação ambiental (como se constroem as equipes, orçamentos, quais são as condições de se desenvolver políticas).

7. Mais estudos de caso (pontuais e mais abrangentes - municipais, estaduais e federais) da materialização das políticas públicas de educação ambiental com vistas a traçar diagnósticos e mapeamentos.

8. Os diferentes interesses da sociedade civil em jogo na definição das políticas de educação ambiental (relação das políticas de EA com as demandas dos movimentos sociais, sobretudo, ligados à educação).

9. Pesquisas enfocando os aspectos ambientais e educacionais, em especial aquelas que avaliam os resultados e/ou consequências das políticas públicas quanto a tais aspectos.

10. Análise dos resultados das políticas públicas (considerando a carência na divulgação dos resultados das políticas públicas pelo próprio Estado). 
11. Buscar explicitar elementos resultantes da investigação que indiquem perspectivas de uma efetiva emancipação humana, evitando, com isto, a desilusão e o desânimo (tanto para o pesquisador quanto para os sujeitos das pesquisas desenvolvidas).

12) Pesquisas que caracterizem a Gestão Ambiental Pública no Estado brasileiro.

13) Pesquisas que investiguem os instrumentos de participação que caracterizam a Gestão Ambiental Pública.

14) Mais estudos sobre a atuação dos sujeitos prioritários da Gestão Ambiental Pública.

15) Investigações sobre a formulação das propostas de Gestão Ambiental Pública (quem são os sujeitos que vem realizando a formulação das políticas públicas para a Gestão Ambiental Pública? Como esses sujeitos vêm atuando?).

16) Trabalhos que estudem a relação entre as políticas internacionais e as políticas nacionais e locais acerca das definições sobre a Gestão Ambiental Pública.

17) Pesquisas que abordem as questões epistemológicas referentes às políticas públicas de EA.

18) Trabalhos que enfoquem as diversas formas de privatização das políticas públicas de EA.

19) Investigações centradas nas conquistas em relação à construção da Gestão Pública Ambiental no Brasil.

20) Pesquisas que investiguem os processos de formulação e implementação das políticas e programas municipais e estaduais de EA.

21) Investigações sobre os limites e possibilidades de fortalecimento da democracia nos processos de formulação da Gestão Ambiental Pública.

22) Trabalhos que investiguem o regime de colaboração entre instituições públicas para a organização da Gestão Pública Ambiental.

Buscamos abordar, no presente texto, os eixos temáticos número um e o dezessete, ou seja, os conceitos de Estado e sociedade civil nos trabalhos do GDP, bem como as questões epistemológicas inerentes a essas pesquisas e com rebatimentos nas análises das políticas públicas de EA. Nesse sentido, iniciamos o artigo com uma discussão sobre a particularidade do campo de pesquisas sobre políticas públicas em educação ambiental, a partir da constituição da educação ambiental enquanto campo social constituído por disputas teóricometodológicas e ideopolíticas em busca de hegemonia nos debates do mesmo.

Em um segundo momento, são apresentadas discussões acerca do campo de pesquisas em políticas educacionais, a partir dos resultados de uma metapesquisa, nesse campo, que buscou caracterizar suas características e tendências internas. Em seguida, apresentamos algumas concepções dos principais referenciais teóricos (e alguns autores neles situados) acerca dos conceitos de Estado, sociedade civil e políticas públicas. Posteriormente, são analisados os trabalhos do GDP sobre Políticas Públicas de Educação Ambiental, nos EPEAs, entre 2011 e 2019, buscando aprofundar o debate acerca dos referenciais teóricometodológicos adotados pelos pesquisadores do referido campo.

A questão do método e a preocupação com o rigor das pesquisas são centrais nas Ciências Sociais. Mesmo reconhecendo a grande diversidade de paradigmas e referenciais teórico-metodológicos que estão presentes nas pesquisas, e que cada qual assume particularidades em relação aos demais, é relativamente consensual que critérios de rigor teórico-metodológico balizem a avaliação da qualidade das pesquisas. Do mesmo modo que, como nos lembra Netto (2011, p. 9), "não é casual que sempre que elas [as ciências sociais] tenham sido objeto de questionamento, o debate metodológico esteve em primeiro plano". Com o intuito de avançar no debate sobre critérios gerais de rigor para as pesquisas científicas, Ivenicki e Canen (2016, p. 26-27) chegam a apresentar alguns, a saber: (1) "haver um problema de pesquisa e não apenas um tema"; (2) "haver uma justificativa que mostre a 
relevância do tema para o campo de estudos, assim como a motivação pessoal/profissional e lacunas do conhecimento que o estudo procure cobrir"; (3) "exibir a clarificação dos valores e do paradigma que move o pesquisador, de forma que o leitor possa compreender a partir de que conjunto de crenças a pesquisa foi desenvolvida e apresentar suas críticas e interpretações alternativas"; (4) "mostrar a necessidade de que a análise de dados seja feita de forma que o pesquisador apresente evidências para suas interpretações e não apenas as interpretações propriamente ditas [...], de modo a permitir reflexões alternativas, por parte do leitor". Nessa direção, temos sustentado a importância do aprofundamento teórico-metodológico das pesquisas sobre políticas públicas em educação ambiental (KAPLAN; LAMOSA, 2018).

Além disso, compreendemos que há uma disputa no campo teórico da educação ambiental (MAIA; TEIXEIRA; AGUDO, 2015). Constatação, aliás, feita, há tempos, por diversos pesquisadores de tradições teóricas distintas (GUIMARÃES, 2004; CARVALHO, 2004; LOUREIRO, 2004; LAYRARGUES; LIMA, 2014), os quais identificam uma vertente crítica dentro do campo em contraposição a uma EA hegemônica, de caráter conservador, tradicional, convencional, reprodutor, conservacionista, pragmático etc. Entretanto, apesar dessa diferenciação inicial, um debate que vem sendo colocado dentro do campo da EA é quanto à natureza da EA Crítica, expresso pela pergunta educação ambiental crítica: crítica de quêe? (TREIN, 2012).

Em uma pesquisa que buscou avançar nessa compreensão, Lopes (2019) analisou trabalhos e entrevistou os autores mais citados nos EPEAs. Em sua investigação, concluiu que a EA Crítica é disputada por diferentes tradições teóricas, tais como o materialismo históricodialético, a hermenêutica, a fenomenologia, a teoria da complexidade, os estudos culturais, estudos decoloniais etc. A diversidade de vertentes teóricas tem implicações nas distintas concepções acerca de conceitos como crítica, transformação, conscientização, emancipação etc.

Em termos de temáticas, há desde investigações mais pautadas em estudos de caso a estudos mais amplos sobre políticas, leis e/ou programas federais, estaduais ou municipais de educação ambiental (LOPES, 2019, p. 109). Em relação aos aspectos metodológicos, os instrumentos de coleta de dados e de procedimentos de análise também têm sido bastante diversificados: dentre os primeiros, no VIII EPEA foram destacados a pesquisa histórica, a pesquisa documental, a observação, a entrevista semiestruturada e a aplicação de questionário; como procedimentos de análise, identificou-se a análise de conteúdo e a análise do discurso (LOPES, 2019, p. 110-111).

Quanto aos referenciais teórico-metodológicos, no VIII EPEA os coordenadores do GDP constataram a presença marcante do materialismo histórico dialético, notado desde as edições anteriores do GDP (FERRARO JR, 2012; SANTANA, 2014; SANTANA; LAMOSA, 2016; KAPLAN; LAMOSA, 2018). Certamente, são muitas as demandas de aprofundamento das pesquisas sobre políticas públicas em EA. Vejamos, agora, os debates relevantes de fundo, no campo de políticas sobre políticas públicas em educação e, especificamente, em educação ambiental.

\section{Algumas considerações sobre o campo de pesquisas sobre políticas públicas de educação}

Para que os pesquisadores sobre políticas públicas de educação ambiental possam ter mais elementos para compreender a natureza de seu objeto de estudo, consideramos ser extremamente relevante conhecerem mais a fundo o campo de pesquisas sobre políticas públicas de educação, já que a EA trata-se de uma área específica da educação. Desse modo, tomamos, aqui, alguns estudos de metapesquisa, isto é, "a análise de um conjunto de artigos que resultaram de investigações de natureza teórica ou empírica" que vem sendo realizados 
por Mainardes (2017, 2018a, 2018b). Esse pesquisador das políticas educacionais vem se dedicando a caracterizar esse campo, tendo analisado 140 artigos de autores brasileiros publicados em sete periódicos entre 2010 e 2012.

Uma primeira constatação desse levantamento sobre o objeto de estudos da política educacional é a de que "a literatura latino-americana sobre este tema ainda é bastante recente" (GOMES; OLIVEIRA, 2012; SOUZA, 2016; MAINARDES, 2015b; TELLO, 2015 apud MAINARDES, 2018a, p. 187). Por sua vez, na literatura de língua inglesa "é uma temática que aparece de forma tangencial nos artigos" (BARROSO et al., 2007; EMAD; ROTH, 2009; FENWICK; EDWARDS, 2011 apud MAINARDES, 2018a, p. 187). Segundo esse pesquisador, "o campo da política educacional está em permanente expansão e continuamente em construção" (MAINARDES, 2018b, p. 3). Isso pode ser observado por meio do aumento do número de grupos de pesquisa, linhas de pesquisa em Programas de Pós-Graduação em Educação, criação de redes de pesquisa, aumento de publicações, criação de periódicos especializados e realização de eventos específicos sobre políticas educacionais (MAINARDES, 2018a).

As seguintes questões são abordadas nos estudos sobre as políticas educacionais:
a) Estudos de natureza teórica sobre temas relacionados à política educacional (Estado, neoliberalismo, as relações entre o setor público e o privado, fundamentos teórico-metodológicos da pesquisa sobre políticas educacionais, epistemologias da política educacional, entre outros).
b) Análise de políticas (implementação, avaliação etc).
c) Políticas educacionais e gestão (educacional e escolar).
d) Legislação educacional.
e) Financiamento da educação.
f) Políticas curriculares.
g) Políticas voltadas ao trabalho docente (formação, valorização, carreira, etc).
h) Questões relacionadas às demandas educacionais, oferta, acesso, qualidade, direito à educação, movimentos de luta pela garantia do direito à educação (MAINARDES, 2018a, p. 187).

Quanto aos temas mais recorrentes, em sua metapesquisa Mainardes (2017) levantou que foram, em ordem: (i) financiamento e regime de colaboração; (ii) análise de programas específicos; (iii) Educação Superior: expansão e regulação; (iv) público e privado; (v) avaliação e regulação; (vi) Plano Nacional de Educação; (vii) Política Municipal de Educação; (viii) carreira, remuneração e valorização do professor; (ix) e federalismo. Em relação à natureza da pesquisa, a maioria era de artigos de pesquisa empírica (62\%) e os demais de natureza teórica $(38 \%)$.

Sendo assim, o objeto de estudo da política educacional, ainda segundo Mainardes (2018a, p.189), é a análise das políticas educacionais formuladas pelo Estado, em seus diferentes níveis e esferas (federal, estadual, municipal). Análise, esta, que abrange estudos de natureza teórica, estudos com base empírica e estudos para a superação da realidade.

No que diz respeito aos procedimentos metodológicos, a maioria das investigações de natureza empírica adotou métodos mistos (quantitativos e qualitativos). Os procedimentos mais recorrentes foram, nessa ordem, a análise documental, análise de dados estatísticos (microdados do Inep, dados do Ideb, dados de avaliações do desempenho de alunos de redes estaduais ou municipais, dados de matrículas, tabelas salariais), entrevistas, questionários, observação, grupo focal (MAINARDES, 2017, p. 9).

Mainardes (2018b, p. 3) identificou que ainda são poucos os estudos sobre os referenciais teóricos que têm sido empregados nas pesquisas sobre políticas educacionais. Essa lacuna é bastante preocupante, inclusive porque o conceito e a concepção de política pública de educação do pesquisador afetam "o processo de pesquisa, embora muitas vezes 
este não seja explicitado ou não esteja consciente para o próprio pesquisador" (MAINARDES, 2018a, p. 188).

Assumindo que não existe neutralidade metodológica, Mainardes (2017, p.4) defende que, "ao explicitar suas bases epistemológicas, o pesquisador pode exercer a vigilância epistemológica em sua pesquisa, cuja construção parte da perspectiva e do posicionamento epistemológicos assumidos". Dessa forma, o enfoque epistemetodológico se torna um "fio condutor que articula todos os elementos da pesquisa, ampliando sua coerência, consistência e rigorosidade".

Finalmente, quanto às perspectivas teórico-epistemológicas da amostra analisada por Mainardes (2017, p. 11), o pesquisador identificou que "a maioria dos artigos apresentava uma breve exposição do referencial teórico, sem a preocupação em justificar as escolhas ou ainda em problematizar as teorias a partir dos dados e da análise". Dos 140 artigos, apenas cinco explicitavam uma perspectiva epistemológica, e três explicitavam a perspectiva teórica. Para os demais, a imensa maioria, portanto, "as perspectivas epistemológicas ou teóricas foram depreendidas a partir da leitura e análise dos artigos, pois não havia tal explicitação pelos próprios autores".

Como resultado das perspectivas teóricas dos artigos da amostra analisada, Mainardes (2017) obteve o seguinte: teorização combinada (65,8\%); materialismo histórico-dialético $(7,1 \%)$; sem evidências de fundamentação teórica, isto é, ausência de teorização $(5,8 \%)$; teorização adicionada $(5,0 \%)$; enfoque neoinstitucional, ou seja, institucionalismo normativo, institucionalismo histórico, institucionalismo de redes $(3,6 \%)$; enfoque histórico-sociológico (2,9\%); teoria de Bourdieu (2,1\%); enfoque histórico-filosófico $(1,4 \%)$; enfoque jurídicoinstitucional $(1,4 \%)$; teoria de Foucault $(0,7 \%)$; enfoque funcionalista $(0,7 \%)$; enfoque culturalista $(0,7 \%)$; teoria das Representações Sociais $(0,7 \%)$; teoria crítica $(0,7 \%)$; Análise Crítica do Discurso $(0,7 \%)$; e teoria do discurso de Laclau e Mouffe $(0,7 \%)$. Por teorização combinada, o autor está se referindo a "um esforço de articular teorias ou conceitos oriundos de diferentes teorias, com o objetivo de compor um quadro teórico consistente para fundamentar uma determinada análise" (McLENNAN, 1996 apud MAINARDES, 2017, p. 6).

Em muitos casos, "a combinação resultou em uma fundamentação capaz de subsidiar uma análise coerente e articulada" (MAINARDES, 2017, p. 12). Além disso, de acordo com o pesquisador, "a utilização de referenciais internacionais, em alguns trabalhos, possibilitou uma análise mais ampliada, consistente e diferenciada da temática" (MAINARDES, 2017, p. 13), assim como a adoção de autores clássicos (Weber, Bourdieu, Foucault, por exemplo) "permitiu o aprofundamento analítico e a ampliação da argumentação". Em contraposição, a teorização tornou-se "relativamente frágil, com consequências na análise e discussões" nos trabalhos que se limitaram a utilizar autores do mesmo tema ou autores contemporâneos.

Por sua vez, a categoria teorização adicionada

[...] significa a adoção mais ou menos aleatória de teorias, conceitos, ideias de diferentes teorias e perspectivas epistemológicas, resultando em um conjunto de ideias e conceitos sem coerência, unidade e articulação teórica. O simples adicionamento e a sobreposição de ideias de diferentes autores resultam em uma tentativa fracassada da definição de um referencial teórico, o qual pode ser considerado frágil, desarticulado e epistemologicamente pouco coerente (McLENNAN, 1996 apud MAINARDES, 2017, p. 6).

Dito de outra forma, a "simples agregação de teorias, conceitos ou ideias de autores de diferentes perspectivas teóricas, as quais não são articuladas ou problematizadas" (MAINARDES, 2017, p. 14). É preocupante constatar que cerca de 5\% dos artigos dessa amostra incorrem nessa "escolha aleatória e pouco consciente" de teorias, ideias ou conceitos. $\mathrm{O}$ autor em tela distingue a teorização combinada da teorização adicionada, considerando a primeira uma forma de pluralismo epistemológico, enquanto a segunda se trata de um tipo de 
ecletismo teórico. O pluralismo epistemológico, para esse autor, "merece ser debatido e aprofundado" (MAINARDES, 2017, p. 17), tratando-se de uma "tentativa de composição de um quadro teórico consistente, a partir da combinação de conceitos de teorias distintas, os quais fazem sentido e formam um referencial consistente". Nesse sentido, diferencia da teorização adicionada e seu ecletismo epistemológico, à medida que este resulta em um "uso aleatório de ideias ou conceitos".

Em termos de posicionamento epistemológico, o pesquisador definiu as seguintes categorias: analítico $(55,7 \%)$; crítico-analítico (20\%); empirista $(14,3 \%)$; crítico-normativo $(6,4 \%)$; crítico-radical $(2,9 \%)$ e culturalista $(0,7 \%)$. O posicionamento epistemológico analítico indica artigos que "apresentam análise de dados ou o desenvolvimento de um ensaio teórico, devidamente fundamentado em um referencial teórico", mas "de modo geral, não apresentam um posicionamento mais explícito com relação à política investigada (ou às questões abordadas ou dados analisados)". Essa pesquisa observou que "quando o quadro teórico construído pelo autor baseia-se mais em pesquisas sobre o próprio tema da pesquisa e não em uma teoria mais densa e consolidada, a análise torna-se mais limitada". Além disso, foram verificados "níveis diferenciados de análise: mais ou menos sofisticadas, análises com maior ou menor integração entre teoria e dados, com maior ou menor nível de originalidade e argumentação" (MAINARDES, 2017, p.15).

Por sua vez, os artigos categorizados enquanto crítico-radicais "apresentam análises mais aprofundadas acerca da política investigada e buscam desvelar as contradições das políticas e suas consequências para as classes sociais e para o futuro da sociedade". Além disso, de modo geral, ao oferecerem uma visão mais ampla e aprofundada, são artigos que podem servir de base para outros estudos. Tais artigos foram, também, classificados como nível de compreensão, no que se refere aos níveis de abordagem/abstração (MAINARDES, 2017, p. 15).

Com relação aos níveis de abordagem/abstração, os artigos foram agrupados em três categorias básicas: descrição $(81,4 \%)$, análise $(15,0 \%)$ e compreensão $(3,6 \%)$. Nos estudos analíticos, "os dados ou ideias são trabalhados, categorizados, comparados. As teorias não são meramente aplicadas, pois o esforço de análise resulta na geração de conceitos, de categorias, de tipologias, de generalizações empíricas" (MAINARDES; TELLO 2016 apud MAINARDES, 2017, p. 15). Os estudos descritivos

São aqueles que apresentam um conjunto de ideias (em artigos de natureza teórica
ou bibliográfica) ou dados empíricos, com pouca análise das ideias ou dados
apresentados. Embora possam apresentar alguma fundamentação teórica, são
estudos com nível reduzido de integração entre teoria e dados. Entre os estudos
descritivos, há aqueles que apresentam um conjunto significativo e relevante de
dados (por exemplo, informações estatísticas), os quais são fracamente explorados à
luz de marcos teóricos. Há também estudos que apresentam resultados de pesquisas
com poucos sujeitos ou bastante voltados a um contexto específico (local). Nesse
caso, o que está em jogo não é a quantidade de sujeitos ou a abrangência da pesquisa,
mas o estilo de abordagem (meramente descritiva).

Por sua vez, os estudos de tipo compreensivos atingem "o nível mais elevado e avançado de abstração" (MAINARDES, 2017, p. 15). Nesse sentido,

São estudos que buscam abordar a temática (teórica ou empírica) de modo mais totalizante, explorando de forma aprofundada as relações e as determinações envolvidas na política investigada ou na questão que está sendo discutida. De modo geral, são estudos que apresentam maior riqueza e profundidade nas análises, podendo inclusive servir de base para outras pesquisas. Nesses estudos, podemos observar uma articulação forte e coerente entre a perspectiva epistemológica, posicionamento epistemológico e enfoque epistemetodológico, mesmo quando a perspectiva epistemológica não é explicitada (MAINARDES, 2017, p. 16). 
Em suma, dentre as principais conclusões dessa pesquisa está a constatação de que "há níveis diferenciados de análise (mais desenvolvidas, menos desenvolvidas, mais preocupadas com a técnica ou mais voltadas a um esforço de teorização a partir dos dados)". Além disso, constatou-se que "o referencial teórico é um elemento essencial para a construção do processo analítico". A teoria tem uma importância enorme na análise de políticas e "a ausência de teoria é um entrave para o pensamento crítico e criativo do pesquisador. Há casos em que o problema central não é a ausência de teoria, mas uma articulação frágil entre a teoria adotada como fundamento e as análises realizadas (pouca integração entre teoria e dados)" (MAINARDES, 2017, p. 16).

A relevância dessa metapesquisa e das classificações e categorias pode ser justificada por algumas razões:

\footnotetext{
a)permitem uma compreensão mais aprofundada das perspectivas teóricoepistemológicas que têm sido empregadas na pesquisa de política educacional e das suas implicações para o fortalecimento da pesquisa nesse campo; b) oferecem uma 'linguagem de descrição' para nos referirmos às pesquisas do campo; c) permitem identificar, com maior clareza, as potenciais tensões e desafios da pesquisa de política educacional, bem como refletir sobre estratégias para o contínuo fortalecimento das pesquisas do campo (MAINARDES, 2017, p. 16).
}

Mainardes (2017, p. 17), com base na metapesquisa realizada, delineou alguns desafios para a pesquisa no campo da política educacional. Em primeiro lugar, o autor aponta para a "necessidade de ampliar o conhecimento acerca dos fundamentos teóricoepistemológicos que têm sido utilizados pelos pesquisadores do campo da política educacional". Ele defende a explicitação da perspectiva teórico-epistemológica como forma de aumentar a consistência da pesquisa, a coerência entre teoria, metodologia, análise de dados e conclusões, bem como podendo aumentar o rigor na pesquisa.

Apesar disso, o autor supracitado reconhece que "a explicitação por si só não garante que os elementos da pesquisa estejam alinhados e coerentes e que o pesquisador efetivamente opere satisfatoriamente com o referencial adotado". Ele conclui esse primeiro desafio, argumentando que o engajamento com uma epistemologia profunda nos relatórios e na prática da pesquisa são aspectos que contribuem para o fortalecimento das pesquisas do campo e para o aumento do nível de rigorosidade e cientificidade. "A clareza teórica e o uso consciente e reflexivo do referencial teórico são alguns aspectos que podem subsidiar a realização de estudos de compreensão". Considerando o campo de pesquisas sobre política educacional ainda recente, em construção, e complexo, à medida que "se caracteriza por ser um projeto científico e ao mesmo tempo um projeto político", o mesmo envolve também "a análise de fenômenos cada vez mais complexos da realidade política, econômica, social e educacional" (MAINARDES, 2017, p. 17-18).

\section{As concepções de Estado, sociedade civil e políticas públicas: categorias centrais para o campo de pesquisas sobre políticas públicas em educação ambiental}

Conforme vimos sustentando ao longo deste artigo, a explicitação e o aprofundamento dos referenciais teórico-metodológicos são tarefas indispensáveis para o desenvolvimento das pesquisas no campo das políticas públicas em educação ambiental. Nesse sentido, buscar a coerência entre os conceitos/categorias e as teorias/epistemologias é decisivo. Algumas categorias são centrais nas pesquisas sobre políticas públicas: Estado, sociedade civil e políticas públicas. Buscamos, nesta seção, apresentar, de modo bastante sintético, algumas das principais conceituações dessas três categorias entre os diferentes paradigmas e alguns de seus 
autores clássicos e outros mais contemporâneos. Tais autores foram escolhidos devido aos seguintes critérios: (a) expressividade dessas perspectivas teóricas e autores dentro do campo de pesquisa sobre as políticas públicas em educação ambiental, com base nos trabalhos vinculados ao GDP Políticas Públicas de EA e nas menções destes pelos participantes das reuniões do GDP; (b) expressividade dessas perspectivas teóricas e autores dentro do campo de pesquisa sobre as políticas educacionais.

Assumido o limite de espaço deste artigo, optamos por selecionar os seguintes paradigmas e, dentro deles, alguns autores clássicos ou mais contemporâneos, de maior destaque em termos da conceituação de Estado, sociedade civil e políticas públicas: a tradição liberal (social-liberalismo e neoliberalismo) e o marxismo (Karl Marx, Louis Althusser, Antônio Gramsci e Nicos Poulantzas). Demos destaque aos autores da tradição marxista devido à relevância desse referencial para o debate sobre as políticas educacionais, algo já evidenciado tanto pela metapesquisa de Mainardes (2017), em que o materialismo históricodialético foi o referencial epistemológico mais utilizado nas pesquisas (após as chamadas teorizações combinadas), quanto dentro do GDP de Políticas Públicas em EA (SANTANA, 2014; FERRARO, 2012 apud SANTANA; LAMOSA, 2016). Como reúne autores com conceituações distintas, algumas compatíveis, outras conflitantes, pensamos ser oportuno apresentar, ainda que de modo sintético, as principais concepções no interior desse paradigma.

Em suma, percebemos, em praticamente todas as diferentes definições, que a conceituação de política pública prescinde o debate sobre as ações elaboradas por grupos sociais organizados mediadas pelo Estado, com finalidades específicas, para o conjunto da sociedade ou para grupos sociais específicos. Nesse sentido, faz-se indispensável que passemos à discussão acerca das categorias Estado e sociedade civil para, então, dar maior concretude ao conceito de política pública, em geral, e de política pública de educação, com o qual cada pesquisador está trabalhando.

Conforme já identificado por Santana e Lamosa (2016), os autores do campo da Educação Ambiental mais citados, no VIII EPEA, em 2015, situam-se no âmbito do materialismo histórico-dialético (Carlos Frederico Bernardo Loureiro, Marília Tozoni-Reis, Phillipe Pomier Layrargues, Rodrigo Lamosa, José Silva Quintas, Lucia Anello). Além disso, também já foi evidenciada (KAPLAN; LAMOSA, 2018) menção de diversos autores marxistas clássicos e contemporâneos pelos participantes do GDP no IX EPEA, em 2017, como centrais em termos dos conceitos de Estado (Karl Marx, Friedrich Engels, Vladmir Vladimir Ilyich Ulyanov Lenin, Antonio Gramsci, Nicos Poulantzas, David Harvey) e sociedade civil (Karl Marx, Antonio Gramsci, Virginia Fontes, Sonia Regina de Mendonça). Por essa razão, damos um peso maior a esses autores, neste trabalho, contudo, sem deixar de apresentar autores de outras perspectivas teóricas.

A categoria Estado é central para as pesquisas sobre políticas públicas, inclusive as de educação ambiental, à medida que são formuladas, planejadas, financiadas, implementadas, avaliadas, modificadas, substituídas, mantidas e/ou aperfeiçoadas, em boa medida, dentro do Estado, em articulação com determinados grupos sociais da sociedade civil. Nesse sentido, defendemos, aqui, a importância de que, a despeito do autor ou perspectiva com que o pesquisador dialogue, se compreenda o Estado em sua dimensão histórica, como produto das relações sociais e da correlação de forças em uma determinada sociedade (KAPLAN; LAMOSA, 2018).

Karl Marx e Friderich Engels foram dois dos intelectuais que mais se debruçaram sobre a problemática do Estado e de sua relação com a sociedade civil. A formulação hegeliana, a despeito da enorme influência, é superada em relação a teoria do Estado na obra de Marx que entende que o mesmo só pode representar a universalidade, como proposto por Hegel, na aparência. 
Assim, o Estado é a instância que diz representar o interesse universal, mas representa o de uma classe. Ele cumpre a universalidade, reproduzindo o interesse da classe dominante. O Estado tem, assim, a aparência da universalidade, mas a sua realidade efetiva é particular, na medida em que ele garante a organização das condições gerais de um sistema social (ou organização da produção) no qual e pelo qual a burguesia existe como classe dominante. Nesse sentido, o Estado é a expressão política da dominação burguesa, ou seja, porque a burguesia tem um controle especial sobre o trabalho no processo de produção capitalista, como classe dominante ela estende seu poder ao Estado e a outras instituições. Dessa forma, o Estado não está acima dos conflitos de classes (CARNOY, 2015).

Seguindo a tradição teórica e política inaugurada por Marx, Engels e Lenin, o dirigente comunista italiano, Antonio Gramsci, também se dedicou a desenvolver a teoria marxista do Estado. No seu entendimento, Estado é igual à sociedade civil mais sociedade política, isto é, "hegemonia encouraçada de coerção" (GRAMSCI, 1930-1932 apud BUCIGLUCKSMANN, 1980, p. 97). Nessa compreensão, o Estado, apesar de estar a serviço da classe dominante que o dirige, não se mantém apenas por meio da força e da coerção legal. Ele exerce sua dominação de um modo mais sutil e eficaz, isto é, pela obtenção de consentimento dos dominados. Isso se dá com a utilização de aparelhos privados de hegemonia. Enquanto a sociedade política ${ }^{4}$, isto é, o Estado em sentido estrito, atua mediante os aparelhos coercitivos de Estado, a sociedade civil irá operar por meio dos aparelhos privados de hegemonia (imprensa, partidos políticos, sindicatos, associações, escola, Igreja). Esses aparelhos objetivam obter o consenso como condição indispensável à dominação. Na leitura gramsciana, o Estado, portanto, tem um importante papel nos campos cultural e ideológico, bem como na organização do consentimento (MILLIBAND apud BOTTOMORE, 2012, p. 136).

Antônio Gramsci formula sua concepção sobre o Estado no sentido de um Estado ampliado ou Estado integral, que não nega a compreensão de Estado desenvolvida por Marx, Engels e Lenin. Conforme Buci-Glucksmann (1980, p. 127-128), no curso de suas obras, Gramsci progressivamente distingue dois conceitos de Estado, ou mais precisamente dois momentos de articulação do campo estatal: o Estado em sentido estrito (unilateral), e o Estado em sentido amplo, dito integral. Em um sentido estrito, o Estado se identifica com o governo, com o aparelho de ditadura de classe, na medida em que ele possui funções coercitivas e econômicas. A dominação de classe é exercida através do aparelho de Estado no sentido clássico (exército, polícia, administração, burocracia). Mas essa função coercitiva é inseparável de um certo papel adaptativo-educativo do Estado, que procura realizar uma adequação entre aparelho produtivo e moralidade das massas populares. Sobre esse aspecto educativo do Estado (Estado educador), Gramsci, no volume 3 dos Cadernos do cárcere Maquiavel: notas sobre o Estado e a política, afirma como papel do Estado educador:

Criar novos e mais elevados tipos de civilização, de adequar a "civilização" e a moralidade das mais amplas massas populares às necessidades do contínuo desenvolvimento do aparelho econômico de produção e, portanto, de elaborar também fisicamente tipos novos de humanidade (GRAMSCI, 2000 apud NEVES, 2005, p. 26).

\footnotetext{
${ }^{4}$ Compreendida como "conjunto de mecanismos através dos quais a classe dominante detém o monopólio legal da repressão e da violência, e que se identifica com os aparelhos de coerção sob controle dos grupos burocráticos ligados às forças armadas e policiais e à aplicação das leis" (COUTINHO, 1996, p. 61). Em outras palavras, "é a arena das instituições políticas no sentido constitucional jurídico" (SASSOON apud BOTTOMORE, 2012, p. 177).
} 
Entendendo que o Estado desenvolve, paralelamente, e, de forma inseparável, ao "funcionamento da coerção", um funcionamento ao nível da ideologia e da economia, isso, necessariamente, passa pelo campo complexo das superestruturas, o que levou Gramsci a formular sua concepção de Estado ampliado. Assim, ao lado do Estado em sentido estrito, Gramsci coloca o Estado em um sentido amplo. O Estado ampliado ou integral pressupõe a tomada em consideração do conjunto dos meios de direção intelectual e moral de uma classe sobre a sociedade, a maneira como ela poderá realizar sua "hegemonia", ainda que ao preço de "equilíbrios de compromisso", para salvaguardar seu próprio poder político, particularmente ameaçado em períodos de crise (BUCI-GLUCKSMANN, 1980, p. 128-29). Assim, "o Estado é todo o conjunto de atividades teóricas e práticas com as quais a classe dirigente justifica e mantém não somente a sua dominação, mas também consegue obter o consenso ativo dos governados" (GRAMSCI, 1955 apud BUCI-GLUCKSMANN, 1980, p. 129).

Louis Althusser foi um filósofo francês de origem argelina, membro do Partido Comunista Francês. Uma das mais conhecidas preocupações desse autor foi compreender a dinâmica do Estado. Ao tratar do poder de Estado, destaca que "o Estado (e sua existência em seu aparelho) não tem sentido a não ser em função do poder estatal". Nesse sentido, é que toda a luta política de classes gira em torno do Estado, "em torno da posse, isto é, da tomada e preservação do poder estatal por uma certa classe, ou por uma aliança entre classes ou frações de classes". Desse modo, o autor justifica a distinção entre o poder estatal ("conservação do poder estatal ou tomada do poder estatal", "uso do Aparelho de Estado pelas classes ou aliança de classes ou de frações de classes", "o objetivo da luta política de classes"), e o Aparelho de Estado (ALTHUSSER,1996, p. 113)

Althusser, então, retoma a distinção entre Aparelho (Repressivo) de Estado e Aparelhos Ideológicos de Estado $^{5}$. Ele argumenta que o termo repressivo sugere que o Aparelho de Estado em questão funciona pela violência, ao menos no limite, já que a repressão, no caso da repressão administrativa, pode assumir formas não físicas (ALTHUSSER,1996, p. 114).

Outro marxista importante que formulou uma teoria sobre o Estado capitalista foi Nicos Poulantzas, filósofo, sociólogo e membro do Partido Comunista da Grécia (KKE). Em um primeiro momento de sua obra, Poulantzas partiu de uma leitura estruturalista de Marx, efetuada por Louis Althusser, para investigar o Estado. Mas, diferentemente de seu então professor, ele concentrou-se mais nas análises das classes sociais e na política do que na teoria marxista como um todo (CARNOY, 2015, p. 131). É importante sinalizar que as teorias de Poulantzas sobre o Estado capitalista sofreram significativas alterações e revisões ao longo dos anos, entre a publicação de Poder político e classes sociais, em 1968, e $O$ Estado, o poder, o socialismo, em 1978. No decorrer de sua obra, Poulantzas foi recorrendo menos a Althusser e mais às formulações de Gramsci.

Um conceito central na teoria de Estado de Poulantzas é o de bloco no poder, o qual dialoga com a problemática da hegemonia conforme desenvolvida por Gramsci. Os intelectuais orgânicos atuam na sociedade civil, podendo se inserir em agências da sociedade política estratégicas às suas respectivas frações da classe dominante. Segundo Nicos Poulantzas (1986), a classe capitalista, ao mesmo tempo em que mantém uma unidade política

\footnotetext{
${ }^{5}$ Estes funcionam pela ideologia (ALTHUSSER, 1996, p. 115). Como instituições que compõem os AIE, ele considera: o AIE religioso (o sistema das diferentes igrejas), o AIE escolar (o sistema das diferentes escolas públicas e particulares), o AIE familiar, o AIE jurídico (o Direito pertence, simultaneamente, ao ARE e aos AIE), o AIE político (o sistema político de que fazem parte os diferentes partidos), o AIE sindical, o AIE da informação (imprensa, rádio, televisão etc.), o AIE cultural (Letras, Belas Artes, desportos etc.).
} 
em relação à classe historicamente antagônica, diferencia-se internamente de acordo com os interesses econômico-corporativos. Esta diferenciação tem uma natureza econômica, mas também política, uma vez que as "frações" possuem interesses específicos e se posicionam no interior do Estado de forma particular (ibidem, 1986). Assim, o bloco no poder é "a unidade contraditória particular das classes ou frações de classe politicamente dominantes, na sua relação com uma forma particular do Estado capitalista" (POULANTZAS, 1986, p. 229).

Em suma, é possível concluir que, embora haja aspectos comuns dentro das teorias marxistas sobre o Estado, há, também, diferentes abordagens e mesmo algumas polêmicas e divergências entre os autores que integram essa tradição teórica. A crítica materialistadialética ao Estado pressupõe considerar sua relação intrínseca com a sociedade civil, que determina sua natureza. Por essa perspectiva, as funções do Estado não estão descoladas de sua natureza de classe, acarretando importantes implicações para pensarmos os papéis das políticas públicas formuladas, implementadas, avaliadas pelo Estado.

Embora trate-se de uma tradição heterogênea, o liberalismo está organizado em dois aspectos que lhe garantem unidade interna: mediante a constituição de uma corrente de pensamento que gira em torno da defesa dos interesses de classe da burguesia, e consistindo em uma tradição centrada no conceito de liberdade, formalmente compreendida apenas em sua dimensão negativa ${ }^{6}$, entendendo que a intervenção do Estado deriva na sua limitação. Para a tradição liberal, liberdade e igualdade são valores opostos, na medida em que um não pode se realizar sem limitar fortemente o outro (BOBBIO, 1993, p. 39 apud MONTAÑO; DURIGUETTO, 2011, p. 50).

Por sua vez, o neoliberalismo retoma o liberalismo anglo-saxão, o liberalismo clássico, puro, inspirado nos princípios do darwinismo social e na concepção de Estado cão-de-guarda (devendo apenas resguardar a integridade física dos indivíduos e garantir suas liberdades), em detrimento da linhagem do liberalismo francês ou continental, baseada no construtivismo social e nos princípios da Revolução Francesa, do Estado ético hegeliano e do socialismo primitivo. Os liberais clássicos postulavam a minimização do Estado e a desregulação do mercado, postulados que foram retomados com as neoliberais de "Estado mínimo" e "mercado livre" (MONTAÑO; DURIGUETTO, 2011, p. 64).

Ainda que não tenha cunhado o termo, Friedrich August von Hayek pode ser considerado fundador dessa vertente do liberalismo, devido ao seu combate ao intervencionismo estatal e a defesa de um retorno ao mercado desregulado. Em $O$ caminho da servidão, publicado em 1944, argumenta que o intervencionismo estatal conduz ao totalitarismo e à perda de liberdade. Nessa obra, para Hayek, as três formas de planejamento estatal - o keynesianismo na Inglaterra, o nazismo na Alemanha e o socialismo na União Soviética - por constituírem limites à liberdade, eram igualmente o "caminho da servidão", por se tratarem de regimes totalitários, na medida em que teriam eliminado as liberdades individuais (MONTAÑO; DURIGUETTO, 2011, p. 60).

Para Hayek, a liberdade é tomada como o valor supremo, ao invés da democracia, da igualdade ou da justiça social. Assim, a menos que se obtenha a liberdade econômica, as outras formas de liberdade (civil e política) se desvanecem. É nesse sentido que Hayek e os demais defensores do neoliberalismo ${ }^{7}$ defendem uma ordem do mercado para reger os

\footnotetext{
${ }^{6}$ Definida por Fromm (1980 apud MONTAÑO; DURIGUETTO, 2011, p.49) como "liberdade de...", isto é, a "ausência formal de impedimentos ou restrições que um sujeito ou instituição possa exercer sobre a pessoa em questão; ausência de intervenção externa no caminho ou na ação das pessoas", diferenciando-a da "liberdade positiva", compreendida como "liberdade para...", um conceito não formal, mas fundamental de liberdade, vista "não com ausência de impedimentos, mas como capacidade de fazer".

${ }^{7}$ Ludwig von Mises, Karl Popper, Milton Friedman, sobretudo.
} 
princípios e valores sociais, inclusive dentro do Estado. Dentro dessa lógica, o mercado concorrencial é compreendido como o motor da liberdade. Ele afirma, também, que a ordem do mercado implica uma "sociedade livre", "sem uma hierarquia comum", sem a intervenção do Estado (HAYEK, 1990 apud MONTAÑO; DURIGUETTO, 2011, p. 61).

Assim, segundo ele, não há motivo para que o Estado faça políticas sociais fora do mercado. Além disso, não há promessas de reintegração no mercado de trabalho para quem não teve mérito ou sorte, indicando o peso da meritocracia, do esforço individual, e do fator sorte. Opera, aqui, tanto a oposição entre igualdade e liberdade (em sua dimensão negativa formal), além da justiça social, quanto a defesa da desigualdade e da concorrência como alavancas para o desenvolvimento social e econômico (MONTAÑO; DURIGUETTO, 2011, p. 62).

Embora haja muitos paradigmas acerca das concepções de Estado que precisam ser estudados, em função do limite deste artigo, procuramos, neste tópico, apresentar as correntes marxista e liberal. A primeira se justifica pelo predomínio do materialismo histórico nas referências teórico-metodológicas nos trabalhos desse GDP, e pela necessidade de ressaltar a heterogeneidade desse paradigma. A segunda se justifica por ser hegemônica nas relações sociais de produção vigentes e pela necessidade de superarmos a falsa divisão entre sociedade e Estado, tão enraizada nos campos da educação e da educação ambiental. Considerando o peso da tradição liberal no campo da educação ambiental, sublinhamos a sua heterogeneidade e sua relevância para o aprofundamento teórico.

\section{Pesquisa em Educação Ambiental e Políticas Públicas}

No que se refere ao tema da educação ambiental e as políticas públicas, o GDP, organizado no EPEA, vem se constituindo como importante fórum de sistematização e aprofundamento teórico-epistemológico no campo da educação ambiental. Neste trabalho, defendemos que o aprofundamento da categoria política pública pressupõe um adensamento teórico dos conceitos Estado e sociedade civil. Esses conceitos foram identificados, desde a nona edição do EPEA, em 2017, pelos pesquisadores que participam desae GDP, como relevantes para o conjunto de pesquisas na educação ambiental que tratam do tema. Não menos importante é compreender as distintas concepções e abordagens que caracterizam a heterogeneidade do próprio campo da educação ambiental, visando escapar de qualquer superficialidade que escamoteia as diferenças e tensões teóricas.

Partindo da sistematização do conjunto de trabalhos do X Encontro Pesquisa em Educação Ambiental (EPEA), neste tópico apresentamos uma aproximação com o necessário aprofundamento dos conceitos de Estado, Sociedade Civil e Políticas Públicas, bem como uma análise comparativa dos trabalhos entre 2011 e 2019, destacando objetivos, referenciais e temas, partindo da sistematização dos referidos Grupos de Discussão (GDP) (FERRARO, 2012; SANTANA, 2014; SANTANA; LAMOSA, 2016; KAPLAN; LAMOSA, 2018).

O GDP EA e Políticas Públicas, entre 2011 e 2015, produziu uma agenda com questões emergidas a partir dos conjuntos de trabalhos inscritos nas três edições realizadas no período (KAPLAN; LAMOSA, 2018, p.113-114). Essa agenda, formada por vinte e dois pontos (SANTANA, 2014; SANTANA; LAMOSA, 2016) reflete o amplo leque de preocupações concernentes ao campo da educação ambiental, expressando-se no conjunto de trabalhos apresentados no GDP, ao longo das últimas edições do EPEA. Como já foi verificado em trabalhos anteriores (SANTANA; LAMOSA, 2016; SANTANA, 2014; KAPLAN; LAMOSA, 2018) esse GDP se caracteriza pela heterogeneidade teórica e metodológica, sendo o volume de trabalhos alterado em cada edição: em 2011, foram doze trabalhos; em 2013, o GDP foi composto por vinte e um trabalhos; em 2015, quatorze trabalhos e, em 2017, foram vinte trabalhos apresentados no GDP. 
O campo da educação ambiental, como toda área das ciências humanas, se caracteriza por um conjunto amplo de referências teórico-conceituais. De acordo com Pierre Bourdieu (2004), o campo científico (como o religioso, artístico ou educacional) é definido como "um campo de forças e um campo de lutas para conservar ou transformar esse campo de forças" (BOURDIEU, 2004, p. 22-23). A principal contribuição teórica de Bourdieu, aqui, reside na incorporação do poder simbólico como dimensão essencial do Estado, isto é, "como local onde se produzem princípios de representação legítima do mundo social". Concebido como uma forma de crença, uma ilusão bem fundamentada, é atribuído ao Estado "o poder de organizar a vida social por meio da imposição de estruturas cognitivas e de consensos sobre o sentido do mundo" (BEZERRA, 2014, p. 489). Nesse sentido, a análise do autor em tela sobre o Estado se inscreve em seu projeto de elaboração de uma teoria geral do espaço social (BEZERRA, 2014, p. 489).

O conceito de campo nos ajuda a entender melhor a reacomodação de forças em disputa no processo de lutas, que se expressa numa diversidade teórico-metodológica no campo da educação ambiental e exige um esforço de aprofundamento conceitual. A pluralidade de referências teórico-conceituais inerente ao campo científico é uma característica tanto do campo de pesquisa em educação quanto no campo de pesquisa em educação ambiental. Para uma melhor compreensão da variedade temática do campo da educação ambiental, passemos para a análise comparativa dos trabalhos do GDP entre 2011 e 2019.

Dos objetivos dos trabalhos do EPEA de 2011 (onze), a maioria deles foi avaliação de programas e políticas no âmbito federal, como política pública, licenciamento, contexto escolar, educação ambiental não formal e implementação. No que se refere aos temas, "pode haver foco em distintos conteúdos (mudanças climáticas, resíduos sólidos, participação), contextos (educação ambiental formal ou não formal) e âmbitos federativos (municipal, estadual, federal)" (FERRARO, 2012, p.141). Sobre os referenciais, a maioria utiliza o materialismo histórico, embora encontremos distintos autores citados nos trabalhos.

Sobre os objetivos dos trabalhos do EPEA de 2013 (vinte e um), Santana (2014, p. 160,162) destaca uma abrangência destes e os verbos "analisar, compreender, refletir, discutir, investigar, esclarecer, pesquisar, verificar, averiguar, relacionar" como os mais presentes. Sobre os temas, foi registrada uma "preocupação predominante com a questão do licenciamento ambiental, notadamente com relação à exploração do petróleo e do gás. Aproximadamente, um terço dos trabalhos". Também, foi destacada "investigação sobre formas de desenvolvimento de uma dada política pública, seja por meio de algum tipo de programa, projeto ou a socialização da política em conselhos" A maioria dos trabalhos usou como referencial teórico o materialismo histórico dialético, com referencial explicitado em quase um terço dos trabalhos. Além disso, a educação ambiental crítica apareceu tanto vinculada ao materialismo histórico quanto a uma crítica emancipatória.

Os objetivos dos trabalhos do EPEA de 2015 (quatorze) expressaram a diversidade como turismo rural, licenciamento, contexto escolar, evidenciando-se, também, a ampliação dos estudos sobre gestão ambiental pública. Sobre os temas, foram divididos em sete eixos: turismo, licenciamento, escola, política pública, estado da arte, controle social e unidade de conservação. Destes, três são de licenciamento, três são de contextos escolares e três são de políticas públicas, o que se explica, em parte, pelo aumento significativo de políticas estaduais e municipais e avanços no âmbito do licenciamento (SANTANA; LAMOSA, 2016). Sobre os referenciais, destacamos uma ruptura analítica dos sistematizadores, pois os autores mais citados foram classificados entre autores do materialismo histórico dialético e da EA crítica.

No que se refere aos objetivos dos trabalhos do EPEA de 2017 (vinte e cinco), destacamos uma ampliação destes, variando conforme amadureceram debates epistemológicos e teóricos no campo das políticas públicas, que foram sistematizadas em 
eixos "unidades de conservação, políticas públicas (Internacional, Federal, Estadual e Municipal), contexto escolar, controle social, Justiça Ambiental e Estado da arte do campo" ficando sem trabalhos os eixos anteriores turismo e licenciamento (KAPLAN; LAMOSA, 2018, p.116). Destes, o eixo que mais tem trabalhos (nove) é o de políticas públicas.

Na décima edição do EPEA, realizada em 2019 na Unidade Federal de Sergipe (UFS), em Aracajú/SE, foram apresentados nove trabalhos no GDP Educação ambiental e Políticas Públicas, significando uma queda no número de trabalhos apresentados nas últimas edições. Os objetivos dos trabalhos inscritos no GDP foram bem diversos, mantendo uma tendência das edições anteriores: $1^{\circ}$ ) avaliar a implantação e implementação do Projeto Salas Verdes no estado de São Paulo (trabalho.$^{\circ}{ }^{56}$ ); $2^{\circ}$ ) contextualizar a formulação das políticas públicas no âmbito educativo, analisando a relação entre a educação e as políticas públicas vigentes (trabalho n. ${ }^{\circ}$ 89); $3^{\circ}$ ) levantar as concepções de Meio Ambiente, Educação Ambiental e Sustentabilidade de funcionários públicos de sete Secretarias Municipais em Santa Cruz Cabrália/Bahia (trabalho n. $\left.{ }^{\circ} 105\right) ; 4^{\circ}$ ) analisar e problematizar as dimensões de Espaço Físico, Gestão e Currículo do Programa Escolas Sustentáveis, do Governo Federal (trabalho n. $\left.{ }^{\circ} 107\right) ; 5^{\circ}$ ) apresentar os resultados de uma pesquisa documental sobre a educação ambiental na óptica da Matemática (trabalho $\left.\mathrm{n}^{\circ}{ }^{\mathrm{O}} 113\right) ; 6^{\circ}$ ) conhecer o quantitativo de escolas públicas de Mato Grosso do Sul com ações de apoio à essa Comissão (trabalho n. $\left.{ }^{\circ} 124\right) ; 7^{\circ}$ ) investigar, a partir das informações disponíveis na internet, se os/as gestores/as dos Parques Nacionais Brasileiros estão promovendo práticas de Educação Ambiental (trabalho n. ${ }^{\circ} 130$ ); $8^{\circ}$ ) refletir sobre uma educação ambiental crítica (EA-Crítica), capaz não só de interpretar a realidade socioambiental, mas, sobretudo, de transformá-la (trabalho n. ${ }^{\circ} 181$ ); $9^{\circ}$ ) demonstrar, no presente trabalho, uma reflexão sobre instrumentos capazes de, através da formação de uma consciência ambiental, transformar a sociedade (trabalho n. ${ }^{\circ} 212$ ).

Esse conjunto de nove trabalhos se caracterizaram por escolhas variadas de objetos: educação ambiental e escola, reflexões teóricas, Parques Nacionais, PRONATEC, Com-Vida e relação específica entre educação e as políticas públicas vigentes, num rico repertório de pesquisas em diálogo com a agenda de investigação proposta pelo próprio GDP. No que diz respeito às distintas metodologias identificadas, foi possível observar a preponderância das pesquisas de tipo documental, mesmo considerando a diversidade que também já havia sido verificada em fóruns anteriores.

Foram identificados: 1) pesquisa documental sobre Projetos Políticos Pedagógicos de duas Salas Verdes do Estado de São Paulo (trabalho n. ${ }^{\circ}$ 56), acerca do Programa Escolas Sustentáveis (trabalho n. ${ }^{\circ}$ 107), sobre a educação ambiental na ótica da matemática com base nos documentos das políticas federais (trabalho $\mathrm{n}^{\circ}{ }^{\circ} 113$ ), análise documental dos planos de ação do COM-Vida no Mato Grosso do Sul (trabalho n. ${ }^{\circ}$ 124) e análise documental do Projeto Pedagógico do Curso (PPC) Técnico em Meio Ambiente do Instituto Federal Fluminense (IFF) (trabalho n. ${ }^{\circ}$ 181); 2) Estudos bibliográficos (trabalho n. ${ }^{\circ}$ 89); 3) aplicação de questionário para servidores municipais (trabalho n. ${ }^{\circ} 105$ ); 3) revisão bibliográfica sobre a construção das Políticas Ambientais Brasileiras, o processo de instituição dos Parnas no Brasil e sobre os marcos legais da Educação Ambiental (Trabalho n. ${ }^{\circ}$ 130); 4) e revisão teórica sobre educação ambiental e direitos humanos (trabalho n. ${ }^{\circ}$ 212). A maioria dos trabalhos realizou pesquisa documental (55\% dos trabalhos) e, mesmo considerando o baixo número de trabalhos apresentados nesta edição, é possível perceber a diversidade de políticas analisadas no GDP dessa edição.

As temáticas abordadas foram diversas, desde trabalhos que analisaram programas como salas verdes, passando por temáticas envolvendo educação ambiental e direitos humanos, até pesquisas que investigaram políticas federais como o PRONATEC, seguindo uma tendência verificada nas edições anteriores. Desses nove trabalhos, os conceitos Estado e sociedade civil, objeto da reflexão proposta neste artigo, foram citados por seis autores. Em 
nenhum dos trabalhos, porém, há uma definição precisa de ambos os conceitos, que são trazidos nos textos sem serem explicitados, seja pelos próprios autores ou por meio de alguma referência acadêmica. A ausência da definição conceitual não impediu que os autores trouxessem análises acerca das políticas públicas, apresentadas de distintas maneiras.

$\mathrm{Na}$ décima edição do EPEA (2019), cinco trabalhos abordam o tema das políticas públicas, trazendo a categoria para a análise. O primeiro trabalho (56) tem em Loureiro (2008) sua principal referência teórica e ressaltou, numa análise que o aproxima de referenciais do materialismo histórico, as relações entre o Estado e os grupos sociais envolvidos, considerando que as disputas sociais indicam possibilidades de alterações na correlação de forças que definem as políticas públicas e o próprio Estado. Nessa primeira citação, os autores compreendem o Estado como expressão das lutas, ou seja, como resultante dos conflitos que estruturam a sociedade e, portanto, uma relação social historicamente definida. Entretanto, a imprecisão conceitual se reflete na segunda menção ao conceito Estado.

De acordo com os autores, citando Azevedo (1997), "quando uma questão passa a ser discutida e visibilizada pela sociedade e reivindicada pela população, ela exige a atuação do Estado" (trabalho n.56). Nessa segunda menção, o Estado aparece como uma entidade abstrata, etérea e separada da sociedade, portanto filiada ao referencial não classista. Além disso, a definição do conceito Estado está mais próxima da conceituação liberal, o que torna relevante o aprofundamento conceitual tendo em vista que os autores mesclaram acepções opostas do conceito no mesmo trabalho. Enquanto na primeira menção os autores definem o Estado com base no materialismo histórico, no segundo momento o Estado é apresentado como sujeito e árbitro dos conflitos sociais: trata-se de uma mistura teórica ou teorização combinada (MAINARDES, 2018). Se a concepção de Estado de Azevedo (1997) se aproxima da tradição do liberalismo heterodoxo, então extingue a contradição capital x trabalho, dispensando, assim, as premissas do marxismo.

Nos demais trabalhos (trabalho n..$^{\circ} 89$, n. $^{\circ} 124$, n. ${ }^{\circ} 130$ e n. ${ }^{\circ} 212$ ) os autores indicaram a necessidade de construir as ações a partir de atos entre Estado e Sociedade (trabalho ${ }^{\circ}{ }^{\circ} 89$ ); uma mediação entre Estado e sociedade, citando Sorrentino (2005), ao afirmar que as políticas públicas se dão por intervenção direta, por regulamentação, ou contratualismo (trabalho n. $\left.{ }^{\circ} 124\right)^{8}$; por meio da criação de agências e órgãos, o Estado [...] difundia suas ideias de como resolver problemas (trabalho n. $\left.{ }^{\circ} 130\right)^{9}$; e o último citou Beck (2010), sublinhando que tanto os Estados quanto os particulares (...) ocultam e dissimulam-nos para atender aos interesses econômicos e políticos (trabalho n. $\left.{ }^{\circ} 212\right)^{10}$. Em todos esses textos a referência do conceito de Estado, embora não seja apresentada de forma direta, se aproxima da perspectiva liberal heterodoxa, que compreende o Estado como regulador da ordem social e, em função dessa caracterização, apartado da sociedade.

No que se refere ao conceito de sociedade civil, apenas três trabalhos (n. ${ }^{\circ} 56, \mathrm{n}^{\circ} 89$ e o n..$^{\circ}$ 105) o mencionam. O primeiro trabalho (n. ${ }^{\circ}$ 56) apenas trata da participação voluntária no projeto Salas Verdes de moradores da sociedade civil; no segundo trabalho (n. 89), os autores citam a lei N. 9.795/99 (PNEA) para afirmar que a sociedade civil composta por indivíduos comuns pode se relacionar com o desenvolvimento, mas não pode (...) documentar participando da tomada de decisão para a promulgação das leis $\left(\mathrm{n} .^{\circ}\right.$ 89) ${ }^{11}$. A abordagem dada ao conceito Sociedade Civil se aproxima da concepção liberal, entendendo-a como uma

\footnotetext{
${ }^{8}$ Demais autores citados pelo trabalho N. 124: WIZIACK, S., VARGAS, I., ZANON, A., 2013; SORRENTINO, 1995, 2005.

${ }^{9}$ Demais autores citados pelo trabalho N. 130: FONTENELE, A. C. F., 2013; LIMA, 2011.

${ }^{10}$ Demais autores citados pelo trabalho N. 212: SACHS (2009).

${ }^{11}$ Autor também citado: SOUZA, C., 2003.
} 
instância separada do Estado, que não se expressa na luta ideológica nos processos decisórios característicos da vida em sociedade. No terceiro trabalho (n. $\left.{ }^{\circ} 105\right)^{12}$ que citou Fonseca (1999), salientou que tal discussão [ambiental] ganha espaço na sociedade civil em diversas partes do mundo; falam da ideia de uma sociedade civil copartícipe do processo de gestão. Nesse trabalho, defende-se que uma cidade sustentável exige negociação entre sociedade civil, setor público e setor privado (n. $\left.{ }^{\circ} 105\right)$, compartimentando em setores que estariam apartados da sociedade civil. Observamos, então, um processo de amadurecimento do GDP EA e políticas públicas que, desde 2011, vem debatendo sobre os usos de referenciais teóricos.

Os elementos da comparação que destacamos seriam em torno de três eixos: aumento de estudos sobre políticas públicas em variadas temáticas; amadurecimento no debate epistemológico e teórico sobre políticas públicas, Estado, sociedade civil; e novas questões para integrar a agenda produzida pelo GDP. Considerando esse histórico do GDP entre 2011 e 2019, os temas foram mais marcados por uma maior distinção entre uma crítica liberal e uma crítica marxista. Esse grau de clareza foi possível, também, com o aumento do rigor analítico em trabalhos de natureza empírica, necessária para o adensamento teórico e para o preenchimento das lacunas existentes.

Nesses trabalhos, no que se refere aos problemas de pesquisas, identificamos uma tendência de mais rigor analítico, o que também ajuda a pensar em questões, abre novas trilhas investigativas, tendo, ainda, impacto gradual na relevância. No campo da educação ambiental crítica, a análise comparativa demonstrou que existem consequências do rebatimento na prática, pelas concepções de Estado, sociedade civil e política pública. A ampliação dos temas trouxe mais questões, alimentadas por evidências que emergem da natureza empírica predominante, ajudando a definir o problema de pesquisa. Apesar da maioria dos trabalhos apresentar um referencial teórico-metodológico, importante para o campo, há trabalhos que misturam teorias incompatíveis em análises sobre políticas públicas.

$\mathrm{O}$ amadurecimento no debate epistemológico foi identificado quando se fala em gestão ambiental pública, sendo necessário qualificar o conceito de público, como universalizável, de qualidade e gratuito. A tradição neoliberal defende que as políticas públicas devem ser administradas com base em critérios da iniciativa privada, então para superar essa contradição, o caráter da crítica marxista foi ressaltado nos trabalhos entre 2011 e 2019, como possibilidade de denúncia e anúncio de propostas alternativas. O campo da educação, por exemplo, do qual a educação ambiental faz parte, possui um embate entre os próprios privatistas que defendem a redução da escola pública em parceria com as empresas e os que defendem a completa privatização. Nos referenciais teóricos dos trabalhos, essa é uma lacuna a ser superada nos próprios espaços de debate do campo das políticas públicas de educação e de educação ambiental. Os grupos de pesquisa podem incorporar esses elementos da comparação, no sentido de adensar teoricamente os debates, diferenciando o conceito de público não estatal do conceito de público, permitindo localizar essas definições nas correntes que disputam a hegemonia no campo da pesquisa em educação ambiental.

Foi, enfim, possível perceber com a análise comparativa que autores antes considerados críticos, estão, hoje, inseridos num conjunto de correntes limitadas a um debate dentro dos marcos do sistema sociometabólico hegemônico. Nesse sentido, referenciais teóricos que se dizem críticos acabam por reproduzir a lógica da dominação política, com consequências para a formação acadêmica (no âmbito teórico e epistemológico) e para a militância (no âmbito político). Assim, houve um avanço no campo da educação ambiental

\footnotetext{
12 Demais autores citados pelo trabalho N. 105: SILVA, 2007; FONSECA, S.M., 1999; DIEGUES, 2003; SAUVÉ, 1997 ; SATO, Michèle; CARVALHO, 2009; SORRENTINO, M., 1995; GOES, G. e MORALES, A, 2013.
} 
crítica ao identificarmos e preenchermos as lacunas conceituais quanto às concepções de Estado, sociedade civil e políticas públicas.

\section{Considerações finais}

Esta breve caracterização nos ajuda a desfazer algumas leituras equivocadas que costumam ser feitas. A principal delas é a de relacionar o Estado somente ao interesse público, ignorando que ele está atravessado por interesses privados. Trata-se de uma visão ingênua e idealizada de Estado, que precisa ser desconstruída. Além disso, há movimentos de disputas/tensionamentos e de unidade entre os interesses das frações da classe dominante e, em certa medida, de incorporação de interesses da classe dominada, dentro dos aparelhos de Estado, como forma de assegurar a hegemonia das frações da classe dominante na sociedade. Por fim, cabe frisar que há pontos em comum e divergências teóricas entre os diversos autores marxistas que se dedicaram a formular sobre o Estado capitalista. O objetivo da seção anterior foi apresentar algumas dessas concepções, com vistas nos possíveis diálogos e críticas entre as apropriações dos mesmos.

Do ponto de vista das pesquisas em educação ambiental, as políticas públicas configuram-se como subsídios tanto do ponto de vista de prover recursos para financiar projetos, quanto de definir e referendar concepções particulares de educação, de educação ambiental, de Estado, de sociedade civil e da relação público-privado. As diferentes vertentes de educação ambiental nos permitem compreender como esta vem sendo instituída nos espaços nos quais é trabalhada (escolas, licenciamento, unidades de conservação e demais áreas protegidas, junto aos movimentos sociais, ONGs, empresas etc.). A proposta, aqui, é fomentar essas discussões no campo das políticas públicas de EA, considerando que são bastante escassas as reflexões nesse sentido e por entendermos que se trata de um tema estratégico para pensar a formação e as práticas de EA.

\section{Referências}

ALTHUSSER, L. Ideologia e Aparelhos Ideológicos de Estado: notas para uma investigação. In: ZIZEK, S. (Org.) Um mapa da ideologia. Rio de Janeiro: Contraponto, 1996, p. 105-142.

AZEVEDO, J. M. L. de. A educação como política pública. Autores Associados, 1997.

BECK, U. Sociedade de risco: rumo a uma outra modernidade. São Paulo: 34, 2010.

BEZERRA, M. Sobre o Estado. Rev. hist. (São Paulo), n. 173, p. 487-495, jul.-dez., 2015 http://dx.doi.org/10.11606/issn.2316-9141.rh.2015.98814

BOTTOMORE, T. Dicionário do pensamento marxista. Rio de Janeiro: Jorge Zahar, 2 ed., (2012)

BOURDIEU, P. Os usos sociais da ciência - Por uma sociologia clínica do conhecimento científico. São Paulo: Unesp-INRA, 2004.

BUCI-GLUCKSMANN, Christinne. "Gramsci e o Estado: por uma teoria materialista da filosofia”. Rio de Janeiro: Ed. Paz e Terra, 1980.

CARNOY, M. Estado e teoria política. 17 ed. Campinas: Papirus, 2015.

CARVALHO, L. M. Demandas e agendas da pesquisa em educação ambiental no Brasil: sentidos construídos a partir dos relatos dos Grupos de Discussão de Pesquisa em Educação Ambiental (GDPsEPEAS). Pesquisa em Educação Ambiental, Rio Claro, v. 11, n. 2, p. 146-167, 2016. 
CARVALHO, I. C. M. Educação Ambiental Crítica: nomes e endereçamentos da educação. In: LAYRARGUES, P. P. (Coord.) Identidades da educação ambiental brasileira. Brasília: Ministério do Meio Ambiente, 2004. p. 13-24.

COUTINHO, C. N. "Marxismo e política: a dualidade de poderes e outros ensaios. $2^{\circ}$ Edição. São Paulo: Editora Cortez, 1996.

DIEGUES, A.C. Sociedades e comunidades sustentáveis. São Paulo: Nupaup-USP, 2003.

ENGELS, F. A origem da família, da propriedade privada e do Estado. 3 ed. São Paulo: Centauro, 2006.

FERRARO JR., L. A. Dialogar e digladiar: entre a conflagração e a constituição do campo da pesquisa sobre políticas públicas de educação ambiental. Pesquisa em Educação Ambiental, Rio Claro, v. 7, n. 2, p.133-145, Jul./Dez. 2012.

FONSECA, S.M. Movimento Ambientalista e Desenvolvimento Sustentável, um breve histórico. Anais do III Encontro Nacional de Economia Ecológica, Recife, 1999.

FONTENELE, A. C. F. Natureza, políticas públicas e (re)ordenamento do espaço: interfaces das políticas ambientais em Sergipe. 2013. 358 f. Tese (Doutorado em Geografia) - Universidade Federal de Sergipe, Sergipe, 2013.

FONTES, V. Sociedade civil no Brasil contemporâneo: lutas sociais e luta teórica na década de 1980. In: LIMA, J. C. F.; NEVES, L. M. W. (Orgs.). Fundamentos da Educação escolar do Brasil contemporâneo. Rio de Janeiro: Fiocruz, 2006. p. 201-239.

GOES, G.; MORALES, A. Gestão pública e sustentabilidade: desafios, ações e possibilidades. Fórum Ambiental Da Alta Paulista, s/l, v. 9, n. 4. p.199-212, 2013.

GUIMARÃES, M. Educação Ambiental Crítica. In: LAYRARGUES, P. P. (Coord.) Identidades da educação ambiental brasileira. Brasília: Ministério do Meio Ambiente, 2004, p. 25-34.

IVENICKI, A.; CANEN, A. Metodologia da pesquisa: rompendo fronteiras curriculares. Rio de Janeiro: Ciência Moderna, 2016.

KAPLAN, L.; LAMOSA, R. A. C. A necessária conceituação de Estado para as pesquisas no campo das políticas de educação ambiental: contribuições das perspectivas marxistas. Pesquisa em Educação Ambiental, vol.13, n.1 - pags. 111-130, 2018.

LAYRARGUES, P. P.; LIMA, G. F. C. As macrotendências político-pedagógicas da educação ambiental brasileira. Ambiente \& Sociedade, São Paulo, v. 17, n. 1, p. 23-40, Jan./Mar. 2014.

LIMA, G. F. C. Educação ambiental no Brasil: formação, identidades e desafios. Campinas: Papirus, 2011.

LOPES, P. A. Os sentidos da crítica na educação ambiental crítica. 2019 (122 f.). Dissertação (Mestrado em Educação) - Universidade Federal do Rio de Janeiro. Programa de Pós-Graduação em Educação, Rio de Janeiro, 2019.

LOUREIRO, C. F. B. Educação Ambiental Transformadora. In: LAYRARGUES, P. P. (Coord.) Identidades da educação ambiental brasileira. Brasília: Ministério do Meio Ambiente, 2004. p. 65-84. 
LOUREIRO, Carlos Frederico Bernardo; CUNHA, Cláudia Conceição. Educação ambiental e gestão participativa de unidades de conservação: elementos para se pensar a sustentabilidade democrática. Ambiente \& Sociedade, v. 11, n. 2, 2008.

MAIA, J. S. S.; TEIXEIRA, L. A.; AGUDO, M. M. Educação ambiental como campo de disputas: a necessária discussão epistemológica. Planeta Amazônia: Revista Internacional de Direito Ambiental e Políticas Públicas, Macapá, n. 7, p. 75-87, 2015.

MAINARDES, J. A pesquisa sobre política educacional no Brasil: análise de aspectos teóricometodológicos. Educação em Revista, Belo Horizonte, n 33, e173480, p. 01-25, 2017.

MAINARDES, J. Reflexões sobre o objeto de estudo da política educacional. Laplage em Revista, (Sorocaba), v. 4, n. 1, p. 186-201, Jan./Abr. 2018a.

MAINARDES, J. A pesquisa no campo da política educacional: perspectivas teórico-epistemológicas e o lugar do pluralismo. Revista Brasileira de Educação, Rio de Janeiro, v. 23, e230034, p. 01-20, 2018 b.

MENDONÇA, S. R. O Estado Ampliado como ferramenta metodológica. Revista Marx e o marxismo, Niterói. Universidade Federal Fluminense. v. 2, n. 2, p.27-43, Jan./Jul. 2014.

MONTAÑO, C.; DURIGUetTo, M. L. Estado, Classe e Movimento Social. São Paulo: Cortez Editora, 2a edição, 2011

NETTO, J. P. Introdução ao estudo do método em Marx. São Paulo: Expressão Popular, 2011.

NEVES, L. (Org.). A nova pedagogia da hegemonia: estratégias do capital para educar o consenso. São Paulo: Xamã, 2005.

POULANTZAS, N. Poder político e classes sociais. São Paulo: Martins Fontes, 2a ed. 1986.

SANTANA, L. C.; LAMOSA, R. A. C. Pesquisa em Educação Ambiental e Políticas Públicas: desafios políticos e epistemológicos. Pesquisa em Educação Ambiental, Rio Claro, v. 11, n. 2, p. 105$116,2016$.

SANTANA, L. C. Pesquisa em Educação Ambiental e Políticas Públicas: apontamentos e memória de um processo. Pesquisa em Educação Ambiental, Rio Claro, v. 9, n. 1, p. 156-168, 2014.

SACHS, I. O desenvolvimento sustentável: do conceito à ação, de Estocolmo a Joanesburgo. In: VARELlA, M. D.; BARROS-PLATIAU, A.F. Proteção Internacional do meio ambiente. Brasília: Unitar, UniCEUB e UnB, 2009. P..27-33.

SATO, M.; CARVALHO, I. Educação ambiental: pesquisa e desafios. Porto Alegre: Artmed, 2009.

SAUVÉ, L. Educação ambiental e desenvolvimento sustentável: uma análise complexa. Revista de educação pública, Mato Grosso, v. 6, n. 10, p. 72-102, 1997.

SILVA, R. L. F. O meio ambiente por trás da tela: estudo das concepções de educação ambiental dos filmes da TV Escola. 2007. 267 p. Tese (Doutorado em Educação) - Universidade de São Paulo. Faculdade de Educação, São Paulo, 2007.

SORRENTINO, Marcos; [et. al].. Revista Educação e Pesquisa, São Paulo, v.31, n.2, 2005. 
SORRENTINO, M. Apresentação. Como construir políticas públicas de educação ambiental para sociedades sustentáveis? In: RAYMUNDO, M. H. A.; BRIANEZI, T.; SORRENTINO, M. Como construir políticas públicas de educação ambiental para sociedades sustentáveis? São Carlos: Diagrama, 2015

SOUZA, C. "Estado da Arte" da Área de Políticas Públicas: Conceitos e Principais Tipologias. In: ENCONTRO ANUAL DA ASSOCIAÇÃO NACIONAL DE PÓS-GRADUAÇÃO E PESQUISA EM CIÊNCIAS SOCIAIS (ANPOCS), 21-25 de out, Caxambu /MG2003. https://www.anpocs.com/index.php/papers-27-encontro-2/gt-24/gt14-16/4232-csouza-estado$\underline{\text { da/file }}$

TREIN, E. Educação Ambiental Crítica: crítica de quê? Revista Contemporânea de Educação. Rio de Janeiro, v. 7, n. 14, p.295-308, Ago./Dez. 2012.

WIZIACK, S. R. de C.; VARGAS, I. A.; ZANON, A.M. Programa Escolas Sustentáveis: reflexões para a formação de educadores ambientais no Brasil. In: ENCONTRO DE PESQUISA EM EDUCAÇÃO AMBIENTAL, 7, 2013, Rio Claro. Anais... Rio Claro: UNESP/USP/ UFScar, 2013. p. 1-12. Disponível em: < http://www.epea.tmp.br/epea2013_anais/pdfs/plenary/01361.pdf>. Acesso em: 30 mai. 2020. 